\section{Does menopause start earlier in smokers? Evidence from the Pró-Saúde Study}

\section{A menopausa ocorre mais precocemente entre fumantes? Evidências do Estudo Pró- Saúde}

Paula de Holanda Mendes 1

Eduardo Faerstein 2

Washington Leite Junger 3
1-3 Departamento de Epidemiologia. Instituto de Medicina Social. Universidade do Estado do Rio de Janeiro. Rua São Francisco Xavier, 524. $7^{\circ}$ andar, sala 7.009. D. Rio de Janeiro, RJ, Brasil. E-mail: pauladeholanda@yahoo.com.br

\begin{abstract}
Objectives: cigarette smoking has been the modifiable risk factor most consistently associated with earlier menopause. This preliminary study based on cross-sectional data aimed to analyze the association between smoking status and age of onset of menopause in a Brazilian population.

Methods: a cross-sectional study was carried out with 1,222 female employees of Rio de Janeiro university campuses aged over 35 years who were at risk of natural menopause. A Cox proportional hazards model was used to investigate the association between smoking status and age at the onset of menopause, adjusting for education, parity and alcohol consumption.

Results: current smokers showed a $56 \%$ increase in the risk of menopause, being 1.8 years younger at menopause onset compared with women who had never smoked. However, no differences were observed between former smokers and women who had never smoked. The adjusted median age at menopause was 49.5 years for current smokers and 51.3 years for women who had never smoked $(p<0.05)$.

Conclusions: the results suggest a deleterious but potentially reversible effect of smoking on the age of onset of menopause, which should receive greater attention in tobacco control efforts. Longitudinal analyses of this association will be carried out in the future in a follow-up study of this population.
\end{abstract}

Key words Smoking, Menopause, Women's health, Brazil

\section{Resumo}

Objetivos: o fumo tem sido o fator de risco modificável mais consistentemente associado com a antecipação da menopausa. Este estudo buscou analisar a influência do tabagismo na idade de ocorrência da menopausa em uma população brasileira.

Métodos: estudo seccional realizado com 1122 mulheres acima de 35 anos de idade sob risco de menopausa natural em campi universitários no Rio de Janeiro. Foi utilizado o modelo de riscos proporcionais de Cox para estudo da associação do tabagismo com a idade de ocorrência da menopausa, ajustada para escolaridade, paridade e consumo de álcool.

Resultados: fumantes ativas tiveram risco de menopausa aumentado em 56\%, sendo 1,8 anos mais jovens à menopausa quando comparadas a não fumantes. Entre fumantes ativas, a menopausa ocorreu aos 49,5 anos de idade, e entre nunca fumantes aos 51,3 anos $(p<0,05)$. Nenhuma diferença, no entanto, foi encontrada entre ex-fumantes e não fumantes.

Conclusões: os resultados deste estudo sugerem um efeito deletério, porém potencialmente reversível do fumo na antecipação da menopausa. A possibilidade deste efeito deve ser mais enfatizada em esforços de controle do tabagismo. O seguimento da coorte, em andamento, permitirá análises adicionais dessa associação, de natureza longitudinal.

Palavras-chave Tabagismo, Menopausa, Saúde da mulher, Brasil 


\section{Introduction}

Natural menopause is a landmark event in a woman's life, influenced by factors that advance or delay its occurrence. Its early occurrence has been associated with changes in the risk for various diseases and an increase in overall and causespecific mortality. For every three years added to the age of onset of menopause, a $1.6 \%$ reduction in mortality has been observed. ${ }^{1}$

Multiparity, a higher level of education, oral contraceptive use and moderate alcohol intake have been associated with later menopause. In contrast, a younger age at menopause has been reported among nulliparous women, and among those with shorter menstrual cycles or younger age at menarche. 2,3

Cigarette smoking has been the modifiable risk factor most consistently associated with earlier menopause and this has been confirmed by a recent systematic review. ${ }^{4}$ However, only two Brazilian studies - with inconsistent results - were identified in the literature. In a cross-sectional study involving 456 women aged between 45 and 60 years, no associations were observed between smoking habits and the median age at the onset of menopause. 5 Another study reported that among 775 women aged 40-65 years, the onset of menopause was eight months earlier among smokers, and that the risk of menopause was $40 \%$ higher among those smoking more than 10 cigarettes per day. ${ }^{6}$ Neither study was adequately controlled for potential confounders of the association of interest.

The aim of the current study was to explore the association of smoking status with age at menopause.

\section{Methods}

Our source population consisted of civil servants (2,238 women) at university campuses in Rio de Janeiro, Brazil, who agreed to participate in the longitudinal Pró-Saúde Study, which aims to investigate the role of markers of social position and other dimensions of social life on various domains of quality of life, morbidity, and health-related behaviors. ${ }^{7}$ In this specific sub-study we analyzed crosssectional data collected by means of a multidimensional questionnaire self-administered in Phase 1 (1999) of this longitudinal study. The research protocol was approved on May 10th 1999 (register 224/1999) and October 18th, 2011 (register 0041.0.259.000-11) by the Human Subjects Research (Ethics) Committee of Rio de Janeiro State University. Written informed consent was obtained from all study participants.

Natural menopause was defined by the selfreport as not having menstruated for at least 12 months, excluding situations related to surgery (hysterectomy or oophorectomy) or use of chemotherapy or radiation therapy $(n=207)$.

All women over 35 years of age who were at risk of natural menopause were included in our study. We excluded 680 women aged 35 or younger and 45 women who reported menopause before this age, since they are likely to be cases of disease-related menopause. Forty-two women who did not reveal whether they menstruated or not and 13 who did not give their age at the time they stopped menstruating because of hormonal treatment (HT), chemotherapy (QT), radiotherapy (RT) or reasons other than natural or surgical causes (OR) were also excluded from the study. After additional exclusion of 236 subjects with missing or inconsistent data, the study population consisted of 1,222 women.

Participants older than 35 years of age who still menstruated $(n=1049)$, and those who had not completed the 12-month period of amenorrhea $(n=72)$ were right-censored, and contributed to the analysis from age 36 years until the time they were interviewed. Women who reported surgical menopause $(n=147)$ contributed to the study from age 36 to the age of surgery.

Smoking status was determined by questioning whether the participant had smoked at least 100 cigarettes during her lifetime, and whether she currently smoked. Women were classified as either current smokers, former smokers or women who had never smoked.

Potential confounders of the association between smoking and the age at menopause were considered: parity (childless, 1-2 children, $\geq 3$ children); level of education (elementary school or less, high school, college or higher); body mass index $\left(<21 \mathrm{Kg} / \mathrm{m}^{2}\right.$, $21-25 \mathrm{Kg} / \mathrm{m}^{2}$, > $25 \mathrm{Kg} / \mathrm{m}^{2}$ ); oral contraceptive use (yes, no) and alcohol consumption (number of days and doses per day) during the previous two weeks (none, minimal, moderate-heavy)

Crude medians for the age at menopause were estimated via non-parametric cumulative KaplanMeier survival curves for each smoking status. The independent association between the smoking categories and the age at menopause was estimated via hazards ratios using the Cox semi-parametric model of proportional risks. Variables that maintained the association with the age of menopause with a $p$ value $<0.20$ were retained in the final model. Adjusted medians for the smoking categories were determined graphically from the fitted survival 
curves. The statistical analyses were performed using the survival package of the statistical application $\mathrm{R}$, version 2.11.0.

\section{Results}

The median age of the population study was 43 years. Most women had never smoked (52\%), had 1 or 2 children $(61 \%)$, had a university or higher degree $(54 \%)$ and never consumed alcohol (53\%).
In this study population of 1,222 women, the crude median ages for the onset of natural menopause were 53, 52 and 55 years for those who had never smoked, active and former smokers, respectively. Only alcohol consumption, parity, and education level $(p<0.05)$ were retained in the final model (Table 1). Body mass index and contraceptive use were not associated with the age at menopause $(p>0.20)$ and were thus excluded from the final model.

Table 1

Risk (Hazards ratio) of menopause according to smoking status and selected covariates in a Cox proportional risks model. Pró-Saúde Study, Brazil, 1999.

\begin{tabular}{|c|c|c|c|c|}
\hline Variable & $\mathbf{N}$ & $\%$ & Hazard ratio & $95 \% \mathrm{Cl}$ \\
\hline \multicolumn{5}{|l|}{ Smoking status } \\
\hline Never smoked & 637 & 52.0 & 1.00 & - \\
\hline Ex-smoker & 264 & 22.0 & 0.90 & $0.57-1.42$ \\
\hline Active smoker & 321 & 26.0 & 1.56 & $1.06-2.31$ \\
\hline \multicolumn{5}{|l|}{ Parity } \\
\hline Nulliparous & 255 & 21.0 & 1.00 & - \\
\hline 1-2 children & 747 & 61.0 & 0.46 & $0.30-0.69$ \\
\hline$\geq 3$ children & 220 & 18.0 & 0.47 & $0.30-0.73$ \\
\hline \multicolumn{5}{|l|}{ Education } \\
\hline Elementary or less & 168 & 14.0 & 1.00 & - \\
\hline High school & 393 & 32.0 & 0.66 & $0.46-0.95$ \\
\hline College or more & 661 & 54.0 & 0.48 & $0.32-0.71$ \\
\hline \multicolumn{5}{|l|}{ Alcohol consumption } \\
\hline Never & 647 & 53.0 & 1.00 & - \\
\hline Minimal & 429 & 35.0 & 0.88 & $0.61-1.27$ \\
\hline Moderate & 113 & 9.0 & 0.77 & $0.39-1.50$ \\
\hline Heavy & 33 & 3.0 & 2.03 & $1.06-3.91$ \\
\hline
\end{tabular}

Heavy alcohol consumption was associated with a $103 \%$ increase in the risk of menopause (HR = 2.03; 95\%CI: 1.06-3.91). Women with 1-2 children had a $54 \%(\mathrm{HR}=0.46$; $95 \% \mathrm{CI}$ : 0.30-0.69) reduced risk of menopause, and women with $\geq 3$ children had a $53 \%(\mathrm{HR}=0.47 ; 95 \% \mathrm{CI}: 0.30-0.73)$ reduction in risk, relative to those who were nulliparous. Compared to women with elementary school education or less, those with high school and those with university or higher degrees had a reduction in the risk of menopause, respectively, of $34 \%$ ( $\mathrm{HR}=0.66$; 95\%CI: $0.46-0.95)$ and of $52 \%(\mathrm{HR}=0.48 ; 95 \% \mathrm{CI}$ :

\subsection{2-0.71) (Table 1).}

Among current smokers there was an increase of $56 \%(\mathrm{HR}=1.56 ; 95 \% \mathrm{CI}: 1.06-2.31)$ in the risk of menopause, when compared with those who had never smoked $(\mathrm{p}=0.02)$, while former smoking was not associated with the outcome ( $\mathrm{HR}=0.90 ; 95 \% \mathrm{CI}$ : 0.57-1.42), after adjustment for alcohol consumption, parity and education (Table 1 ).

The adjusted median ages at menopause were 49.5 years for current smokers, 51.7 years for former smokers, and 51.3 years for women who had never smoked (Figure 1). 
Age at menopause and median (in years) according to smoking status adjusted for alcohol consumption, parity, and education. Pró-Saúde Study, Brazil, 1999.

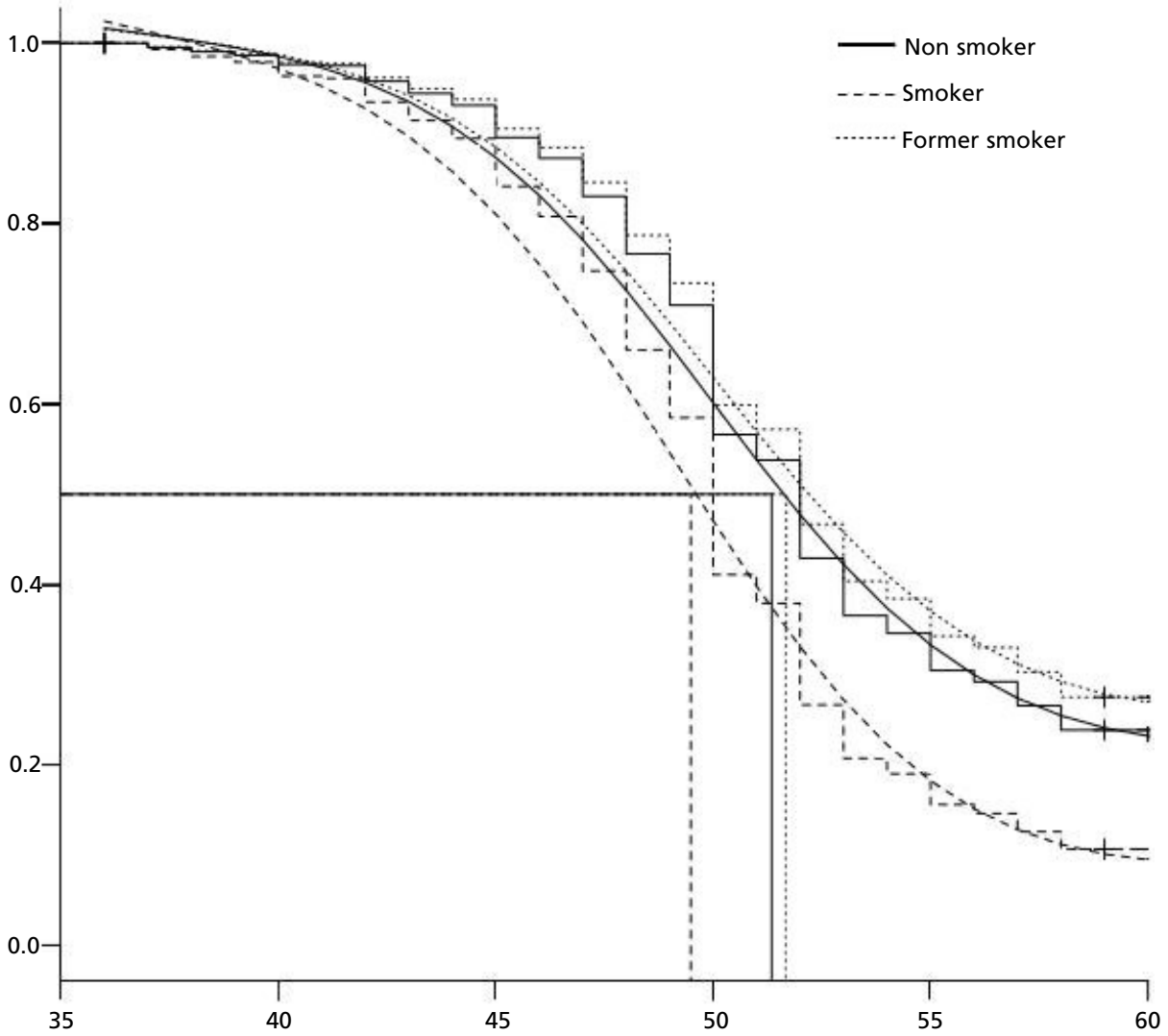

\section{Discussion}

To our knowledge, the present study is the Brazilian study with the largest number - to date - of participants that addresses the association of age at menopause with smoking status.

The influence of smoking on the age of menopause has suggested an effect upon the timing of menopause. ${ }^{8}$ In some of these studies, however, the estimate of this effect was based on the observation of the differences between the crude median of age at menopause for the various categories of smoking history, without taking into consideration the possible effect of confounding variables. 9,10 This may underestimate or overestimate the influence of smoking on the age of menopause.

In the present study, the crude medians for age on menopause obtained using the Kaplan-Meier method differed by nearly one year between active smokers and those who had never smoked, occurring at 52 and 53 years of age, respectively. However, after adjusting for education, parity, and alcohol consumption, the median ages calculated were 49.5 (95\%CI: 48.3-54.1) for active smokers and 51.3 (95\%CI: 49.6-57.0) for women who had never smoked. It could thus be seen that menopause occurred 1.8 years earlier in these women, almost twice the difference observed in the unadjusted analysis. The use of adjusted medians prevents underestimation of the effect of smoking owing to negative confounding factors, thereby estimating, in the most valid way possible, the magnitude of the inverse association with age at menopause.

The survival curves for former smokers and women who had never smoked did not show statistically significant differences, suggesting that, once a woman quits smoking, her age of menopause onset may be roughly equivalent to that of women who 
have never smoked.

Some limitations of our study should be noted. Our results may be affected by measurement error, as some women might not have recalled their exact age by the time they stopped menstruating and/or their smoking history. In addition, smoking status was assessed at baseline and thus may not fully indicate whether or not a woman was a current smoker at menopause. Finally, the information available on alcohol consumption was limited to the previous two weeks. Future research should include more comprehensive and repeated measurements of potential confounders.

With the general trend towards aging human populations, the number of post-menopausal women is growing. Studies that evaluate factors associated with early onset of menopause have thus been receiving increasing attention. Smoking, already

\section{References}

1. Jacobsen BK, Heuch I, Kvile G. Age at natural menopause and all-cause mortality: a 37 year follow-up of 19,731 norwegian women. Am J Epidemiol. 2003; 157 (10): 923-9.

2. Kaczmarek M. The timing of natural menopause in Poland and associated factors. Maturitas. 2007; 57 (2): 139-53.

3. Mikkelsen TF, Iversen SG, Sundby J, Bjertness E. Early menopause, association with tobacco smoking, coffee consumption and other lifestyle factors: a cross-sectional study. BMC Public Health. 2007; 7: 149.

4. Parente RCM, Faerstein E, Celeste RK, Werneck GL. The relationship between smoking and age at the menopause: A systematic review. Maturitas. 2008; 61 (4): 287-98.

5. Pedro AO, Pinto Neto AM, Paiva LHSC, Osis MJ, Hardy E. Age at natural menopause among Brazilian women results from a population-based survey. Cad Saúde Pública. $2003 ; 19$ (1): $17-25$

6. Aldrighi JM, Alecrin IN, Oliveira PR, Shinomata HO Smoking and earlier menopause. Rev Assoc Med Bras. 2005; 51 (1): 51-3.

Recebido em 9 de maio de 2013

Versão final apresentada em 27 de agosto de 2013

Aprovado em 25 de setembro de 2013 established as responsible for multiple effects deleterious to health, constitutes one of the risk factors that have so far been identified as associated with early menopause. The fact that this is a reversible effect increases the relevance of promoting smoking cessation, both in public health and clinical settings.

Smoking is already established as a major risk factor for multiple adverse health outcomes. In relation to age at menopause, the results of the present study involving Brazilian women corroborate findings in other populations. It is especially important to note that these results suggest a deleterious but potentially reversible effect of smoking in relation to earlier menopause. With the ageing of the Pró-Saúde cohort, longitudinal analyses of this association will be conducted in order to confirm our preliminary findings.

7. Faerstein E, Chor D, Lopes CS, Werneck LG. The ProSaude Study: general characteristics and methodological aspect. Rev Bras Epidemiol. 2005; 8 (4): 454-66.

8. Li L, Wu J, Pu D, Zhao Y, Wan C, Sun L, Shen CE, Sun W, Yuan Z, Shen Q, He X, Jiang J, Luo N, He Y, Qian Q, Cai $\mathrm{P}$, Zhang M. Factors associated with the age of natural menopause and menopausal symptoms in Chinese women. Maturitas 2012; 73 (4): 354-60.

9. Kaczmarek M. The timing of natural menopause in Poland and associated factors. Maturitas 2007; 57 (2): 139-53.

10. Cramer DW, Harlow BL, Xu H, Fraer C, Barbieri R. Crosssectional and case-controlled analyses of the association between smoking and early menopause. Maturitas. 1995; 22 (2): 79-87. 